JURNAL ILMU KESEHATAN BHAKTI HUSADA:

HEALTH SCIENCES JOURNAL

VOL. 12 NO. 02, DESEMBER 2021

DOI: $10.34305 / \mathrm{JIKBH} . \mathrm{V} 12 \mathrm{I} 2.342$
Ciptaan disebarluaskan di bawah

Lisensi Creative Commons Atribusi-

NonKomersial-BerbagiSerupa 4.0

Internasional.

\title{
YOGA PRANAYAMA SEBAGAI UPAYA REHABILITATIF PARU PENDERITA PENYAKIT PARU OBSTRUKTIF KRONIK (PPOK): LITERATURE REVIEW
}

\author{
Lutfian \\ Universitas Jember \\ lutfian.ardianysah@aiesec.net
}

\begin{abstract}
Abstrak
Penderita PPOK mengalami gangguan pernapasan persisten dan keterbatasan aliran udara akibat saluran napas tersumbat atau adanya kelainan alveolar yang disebabkan partikel atau gas berbahaya. Prevalensi PPOK di Indonesia berdasarkan data Kemenkes RI tahun 2019 sebesar 3,7\% per satu juta penduduk di Indonesia dengan prevalensi tertinggi pada umur lebih dari 30 tahun. Selain itu, pasien PPOK memerlukan tindakan rehabilitasi paru yang cukup lama untuk menstabilkan kemampuan fungsional paru mereka. Tujuan dari artikel ini adalah untuk mengetahui efektivitas latihan pernapasan yoga pranayama sebagai terapi rehabilitative Paru penderita PPOK. Metode yang digunakan yaitu literature review, berupa artikel yang diperoleh dari media elektronik Google Scholar, Science Direct, NCBl, dan, PubMed dengan kata kunci rehabilitasi paru, yoga pranayama dan PPOK dan rentang tahun publikasi dari tahun 2011-2020. Dari 7 jurnal utama yang di review oleh penulis didapatkan data bahwa pemberian terapi yoga pranayama pada pasien PPOK yang diteliti pada beberapa studi menunjukkan efek perbaikan positif pada fungsi paru-paru dan kapasitas latihan yang berpotensi menjadi program rehabilitasi paru tambahan untuk pasien dengan PPOK. Rehabilitasi paru adalah tindakan yang efektif sebagai upaya peningkatan aspek kualitas hidup, kesehatan fisik serta emosional pada penderita PPOK yang dilakukan melalui pemberian latihan pernapasan yoga pranayama.
\end{abstract}

Kata Kunci $\quad$ : Rehabilitasi paru, PPOK, Yoga pranayama

\section{Pendahuluan}


JURNAL ILMU KESEHATAN BHAKTI HUSADA:

HEALTH SCIENCES JOURNAL

VOL. 12 NO. 02, DESEMBER 2021

DOI: $10.34305 / J I K B H . V 12 I 2.342$
Ciptaan disebarluaskan di bawah

Lisensi Creative Commons Atribusi-

NonKomersial-BerbagiSerupa 4.0

Internasional.
Penyakit Paru Obstruktif Kronis (PPOK) masih menjadi permasalahan utama di dunia dengan mortalitas dan morbiditas yang tinggi (Perhimpunan Dokter Paru Indonesia, 2011). PPOK merupakan penyakit peradangan (inflamasi) progresif pada paru yang ditandai dengan adanya bronchitis kronis, penebalan jalur napas, dan emfisema. Penderita PPOK mengalami gangguan pernapasan persisten dan keterbatasan aliran udara akibat saluran napas tersumbat atau adanya kelainan alveolar yang disebabkan partikel atau gas berbahaya. Penyakit ini menduduki peringkat keempat sebagai penyakit dengan jumlah kematian terbanyak di dunia dan diperkirakan pada tahun 2020 meningkat menjadi peringkat ketiga (Rahman \& Bintari, 2020).

\section{World Health Organization} (WHO) mendata pada tahun 2016 sebanyak 3 juta kematian di dunia disebabkan oleh PPOK. WHO juga menyatakan bahwa 12 negara di Asia Tenggara mempunyai prevalensi PPOK sedang-berat pada usia $>30$ tahun dengan rata-rata $6,3 \%$ (World Health Organization, 2021). Prevalensi PPOK di Indonesia berdasarkan data Kemenkes RI tahun 2019 sebesar 3,7\% per satu juta penduduk dengan prevalensi tertinggi pada umur lebih dari 30 tahun. Prevalensi kejadian PPOK di Indonesia terus meningkat sejalan dengan peningkatan prevalensi perilaku merokok masyarakat di Indonesia. Perilaku merokok masyarakat Indonesia meningkat dari $32,8 \%$ pada tahun 2016 menjadi 33,8\% pada tahun 2018 (Kementerian Kesehatan Republik Indonesia, 2019).

Pemilihan obat dan dosis yang tempat merupakan aspek penting untuk menghindari penggunaan obat secara tidak rasional pada pasien PPOK (Zulkarni et al., 2019). Pemberian dosis, cara dan lama pemakaian yang tepat akan meminimalisir terjadinya efek samping. Terapi farmakologis yang diberikan pada penderita PPOK seperti anti inflamasi, bronkodilator, dan steroid dinilai mampu mengurangi gejala dan menurunkan eksaserbasi PPOK (Zulkarni et al., 2019). Akan tetapi pemberian terapi farmakologis tidak mampu mengatasi penurunan fungsi paru dalam jangka panjang dan memperbaiki kualitas hidup penderita.

Upaya yang dilakukan untuk mengurangi efek samping pengobatan 
JURNAL ILMU KESEHATAN BHAKTI HUSADA:

HEALTH SCIENCES JOURNAL

VOL. 12 NO. 02, DESEMBER 2021

DOI: $10.34305 / J I K B H . V 12 I 2.342$
Ciptaan disebarluaskan di bawah

Lisensi Creative Commons Atribusi-

NonKomersial-BerbagiSerupa 4.0

Internasional. penderita PPOK selain menggunakan terapi farmakologis juga dapat menggunakan terapi non-farmakologis. Rehabilitasi paru dinilai sebagai terapi efektif untuk memperbaiki kesehatan dan meningkatkan kualitas hidup, serta menurunkan jangka waktu rawat inap pasien PPOK. Salah satu terapi nonfarmakologis yang digunakan untuk mengurangi mual, muntah, dan stress pada penderita PPOK yaitu dengan memberikan latihan pernafasan yoga pranayama (Kaminsky et al., 2017; Ranjita et al., 2016; Singh \& Tripathi, 2017).

Menurut penelitian Kaminsky et al., (2017) yoga pranayama dapat meningkatkan kemampuan fungsional paru, kemampuan aktivitas fisik pasien PPOK, menurunkan tanda dan gejala pada penderita PPOK serta ditemukan peningkatan pada kapasitas penghirupan oksigen dan menurunkan stress oksidatif dan tingkat inflamasi didalam paru-paru (Kaminsky et al., 2017). Adapun mekanisme terjadinya perubahan fisik pada individu yang melakukan yoga pranayama adalah diawali dengan terciptanya suasana relaksasi dari alam bawah sadar secara sistematis saat tubuh dalam keadaan rileks yang mendalam (Maharani, 2020).

Meninjau efektivitas dari yoga pranayama sebagai terapi komplementer yang dapat digunakan sebagai agen terapi rehabilitative paru pada penderita PPOK dengan harapan dapat meningkatkan kualitas hidup serta dapat meminimalkan efek samping dan stress akibat pengobatan yang berkepanjangan secara intensif dan berkelanjutan serta potensinya untuk diaplikasikan secara praktis, maka penulis tertarik melakukan studi literatur terkait efektivitas yoga pranayama sebagai terapi rehabilitatif holistik penderita PPOK.

\section{Metode}

Metode penulisan artikel ini menggunakan literature review yang merupakan metode berpikir kritis dan sistematis berdasarkan hasil telaah dari berbagai artikel penelitian dengan menganalisis menggunakan metode logika dan argumen. Pedoman dalam penulisan literature review ini menggunakan metode PRISMA (Preferred Reporting Items for Systematic Reviews and Meta-analyses). Untuk menilai kelayakan artikel untuk di 
JURNAL ILMU KESEHATAN BHAKTI HUSADA:

HEALTH SCIENCES JOURNAL

VOL. 12 NO. 02, DESEMBER 2021

DOI: $10.34305 / J I K B H . V 12 I 2.342$
Ciptaan disebarluaskan di bawah

Lisensi Creative Commons Atribusi-

NonKomersial-BerbagiSerupa 4.0

Internasional. inklusikan dalam studi ini, penulis menggunakan Critical Appraisal Skills Programme (CASP).

Literatur yang digunakan yaitu artikel yang didapat dari media elektronik Google Scholar, Science Direct, NCB1, dan PubMed melalui kata kunci rehabilitasi paru, yoga pranayama dan PPOK. Kriteria yang digunakan dalam pencarian berbahasa Indonesia dan berbahasa Inggris dengan rentang tahun publikasi dari tahun 2011 sampai 2020.

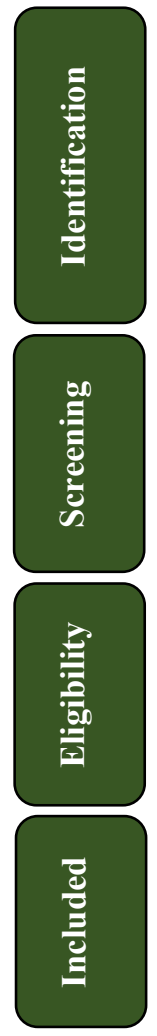

Article relavan yang didapatkan dari database berdasakan kata kunci $(n=50)$ yaitu, Science Direct $(n=18)$, NCB1 $(\mathrm{n}=4)$, PubMed $(\mathrm{n}=4)$, dan Google Scholar $(\mathrm{n}=24)$

Artikel excluded karena tidak sesuai dengan kata kunci pencarian dan kriteria inklusi $(\mathrm{n}=23)$, dan article dikeluarkan karena duplikasi $(\mathrm{n}=9)$

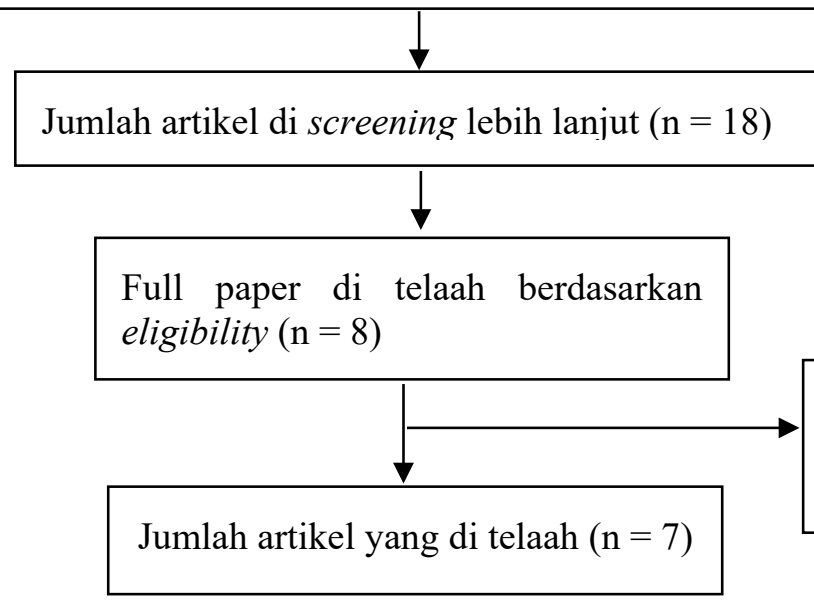

Full paper artikel tidak memenuhi kriteria inklusi dan eksklusi ( $\mathrm{n}=8)$

Bagan 1. Diagram penyeleksian artikel menggunakan PRISMA diagram

\section{Hasil dan Pembahasan}

Tabel 1. Ringkasan deskriptif karakteristik 7 jurnal utama yang digunakan dalam artikel

\begin{tabular}{|c|c|c|c|c|}
\hline $\begin{array}{l}\text { Peneliti, } \\
\text { Tahun } \\
\text { Publikasi }\end{array}$ & Negara & Judul Artikel & Metode & Hasil dan Pembahasan \\
\hline $\begin{array}{l}\text { Ranjita et } \\
\text { al., (2016) }\end{array}$ & India & $\begin{array}{l}\text { Yoga-based } \\
\text { pulmonary } \\
\text { rehabilitation for the }\end{array}$ & $\begin{array}{l}\text { Randomized } \\
\text { Controlled } \\
\text { Trial }(R C T)\end{array}$ & $\begin{array}{l}\text { Penelitian ini menunjukkan } \\
\text { bahwasanya terapi yoga sangat efektif } \\
\text { dalam menurunkan tingkat dyspnea }\end{array}$ \\
\hline
\end{tabular}


JURNAL ILMU KESEHATAN BHAKTI HUSADA:

HEALTH SCIENCES JOURNAL

VOL. 12 NO. 02, DESEMBER 2021

DOI: $10.34305 / J I K B H . V 12 I 2.342$
Ciptaan disebarluaskan di bawah

Lisensi Creative Commons Atribusi-

NonKomersial-BerbagiSerupa 4.0

Internasional.

management of
dyspnea in coal
miners with chronic
obstructive
pulmonary disease:
A randomized
controlled trial

Kaminsky Burlington, Effect of Yoga

et (2017)

of

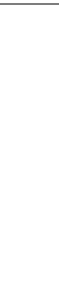

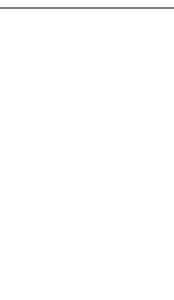

$(\mathrm{p}<0,001)$, tingkat kelelahan

$(\mathrm{p}<0,001)$, nilai nadi $(\mathrm{p}<0,001)$, dan pasien dengan PPOK mengalami peningkatan pada nilai $\mathrm{SpO} 2 \%$ $(\mathrm{P}<0,001)$. Selain itu, intervensi yoga juga dapat meningkatkan kebugaran responden, sehingga Yoga sangat efektif sebagai terapi untuk terapi rehabilitasi paru. $\begin{array}{ll}\text { Randomized } & \text { Penelitian ini menunjukkan hasil } \\ \text { Controlled } & \text { bahwasanya yoga pranayama dapat }\end{array}$ Breathing Controlled (Pranayama) on Trial (RCT) Exercise Tolerance in Patients with Chronic Obstructive Pulmonary Disease meningkatkan fungsional paru, kemampuan aktivitas, menurunkan tanda dan gejala pada penderita PPOK serta ditemukan peningkatan pada kapasitas penghirupan oksigen dan menurunkan stress oksidatif serta tingkat inflamasi didalam paru-paru.

$\begin{array}{llll}\text { Papp et al., } & \text { Sweden, } & \text { Effects of yogic } & \text { Randomized } \\ \text { (2017) } & \text { Europercises on } & \text { Controlled } \\ & \text { functional capacity, Study } \\ \text { lung function and } \\ \text { quality of life in } \\ \text { participants with } \\ \text { obstructive } \\ \text { pulmonary disease }\end{array}$

Hasil penelitian menunjukkan efek yang signifikan terhadap penurunan tingkat kelelahan $(\mathrm{P}=0,04)$, perbaikan emosional $(\mathrm{P}=0,02)$, meningkatkan kemampuan six-minute distance (6MWD) setelah diberikan 12 minggu intervensi, peningkatan $\mathrm{SO}_{2}$, parameter kemampuan fungsional paru, respiratory rate dan tingkat energi setelah pemberian intervensi selama 6 minggu.

\begin{tabular}{llll}
\hline Liu et al., & Shandong, & Effects of yoga & Systematic \\
(2014) & China & with in patients & review dan \\
obstructive chronic & meta- \\
pulmonary disease & analysis
\end{tabular}

Sebanyak 233 pasien yang diberikan intervensi yoga mengalami perbaikan yang signifikan pada FEV1 $(\mathrm{P}=0,04)$, FEV1\% ( $<<0,00001)$, dan 6MWD $(\mathrm{P}=0,001)$. Yoga dapat memberikan efek positif terhadap peningkatan fungsi paru dan kapasitas latihan fisik yang dapat dipertimbangkan menjadi terapi rehabilitasi paru penderita PPOK.

\begin{tabular}{|c|c|c|c|c|}
\hline $\begin{array}{l}\text { Cramer et } \\
\text { al., (2019) }\end{array}$ & Germany & $\begin{array}{l}\text { The risks and } \\
\text { benefits of yoga for } \\
\text { patients with chronic } \\
\text { obstructive } \\
\text { pulmonary disease }\end{array}$ & $\begin{array}{l}\text { Systematic } \\
\text { review dan } \\
\text { meta- } \\
\text { analysis }\end{array}$ & $\begin{array}{l}\text { Sebanyak } 586 \text { pasien yang dianalisis } \\
\text { dalam penelitian ini mengalami } \\
\text { perbaikan yang signifikan terhadap } \\
\text { kemampuan paru-paru yang dilihat } \\
\text { pada nilai FEV1 }(\mathrm{P}<0,001) \text {. } \\
\text { Intervensi Yoga dapat mempermudah } \\
\text { pasien dengan PPOK dalam bernapas }\end{array}$ \\
\hline $\begin{array}{l}\text { Gupta et } \\
\text { al., (2014) }\end{array}$ & $\begin{array}{l}\text { Haryana, } \\
\text { India }\end{array}$ & $\begin{array}{l}\text { Pranayama for } \\
\text { Treatment of } \\
\text { Chronic Obstructive } \\
\text { Pulmonary Disease }\end{array}$ & $\begin{array}{l}\text { Randomized } \\
\text { Controlled } \\
\text { Trial (RCT) }\end{array}$ & $\begin{array}{l}\text { Penelitian ini menunjukkan bahwa } \\
\text { intervensi yoga efektif dalam } \\
\text { menurunkan tanda dan gejala pada } \\
\text { pasien PPOK. Terjadi perbaikan pada } \\
\text { nilai COPD assessment test (CAT) }\end{array}$ \\
\hline
\end{tabular}


JURNAL ILMU KESEHATAN BHAKTI HUSADA:

HEALTH SCIENCES JOURNAL

VOL. 12 NO. 02, DESEMBER 2021

DOI: $10.34305 / J I K B H . V 12 I 2.342$
Ciptaan disebarluaskan di bawah

Lisensi Creative Commons Atribusi-

NonKomersial-BerbagiSerupa 4.0

Internasional.

\begin{tabular}{|c|c|c|c|c|}
\hline & & & & $\begin{array}{l}(\mathrm{P}<0,001), \text { meningkatkan } 6 \mathrm{MWD} \\
\text { serta FEV1 }\end{array}$ \\
\hline $\begin{array}{l}\text { Singh \& } \\
\text { Tripathi, } \\
\text { (2017) }\end{array}$ & $\begin{array}{l}\text { Uttar } \\
\text { Pradesh, } \\
\text { India }\end{array}$ & $\begin{array}{l}\text { Effect of } 6 \text { weeks of } \\
\text { pranayama on } \\
\text { forced expiratory } \\
\text { volume of person } \\
\text { with COPD }\end{array}$ & $\begin{array}{l}\text { Randomized } \\
\text { Controlled } \\
\text { Trial (RCT) }\end{array}$ & $\begin{array}{l}\text { Penelitian ini menunjukkan bahwa } \\
\text { terjadi perubahan nilai yang } \\
\text { signifikan setelah responden } \\
\text { diberikan } 6 \text { minggu intervensi yoga } \\
\text { pranayama pada nilai FEV1 dan } \\
\text { peneliti juga menjelaskan } \\
\text { bahwasanya yoga dapat } \\
\text { meningkatkan kualitas hidup pasien } \\
\text { PPOK }\end{array}$ \\
\hline
\end{tabular}

Yoga Pranayama merupakan salah satu jenis latihan pernapasan dengan teknik mengambil napas secara perlahan dan dalam menggunakan otototot diafragma, sehingga abdomen akan mengalami pengangkatan secara perlahan dan dada akan mengembang secara penuh (Sindhu, 2015). Terjadinya perubahan fisik yang terjadi didalam tubuh merupakan mekanisme awal ketika individu melakukan intervensi yoga pranayama yang kemudian akan menciptakan suasana relaksasi alam sadar dan bawah sadar secara sistematis yang akan membuat suasana rileks yang mendalam (Maharani, 2020). Terciptanya suasana relaksasi akan mampu melepaskan ketegangan otot, ketika tubuh mulai santai, nafas menjadi lambat dan memberikan pengaruh yang sangat positif terhadap keseluruhan sistem sirkulasi. Sistem saraf simpatik akan menerima pesan aman untuk melakukan relaksasi sedangkan sistem saraf parasimpatik akan memberikan respon untuk relaksasi. kemudian, pesan relaksasi akan diterima oleh kelenjar endokrin yang bertanggung jawab terhadap sebagian besar keadaan emosi dan fisik (Balach et al., 2011; Cramer et al., 2019).

\section{Latihan pernapasan yoga} pranayama dapat dilakukan dengan posisi duduk dimana salah satu postur duduk yoga (asana) memaksimalkan posisi tulang punggung yang tegak dari tulang ekor ke puncak kepala. Posisi ini akan memaksimalkan kapasitas ruang ventilasi paru saat mengambil napas serta dapat menjaga agar aliran pernapasan tetap mengalir lancer di sepanjang nadi di daerah tulang punggung (Kaminsky et al., 2017). Saat melakukan teknik yoga pranayama, individu hanya menghirup dan mengeluarkan napas melalui hidung. Adapun pose yang baik untuk melakukan 
JURNAL ILMU KESEHATAN BHAKTI HUSADA:

HEALTH SCIENCES JOURNAL

VOL. 12 NO. 02, DESEMBER 2021

DOI: $10.34305 / J I K B H . V 12 I 2.342$
Ciptaan disebarluaskan di bawah

Lisensi Creative Commons Atribusi-

NonKomersial-BerbagiSerupa 4.0

Internasional. latihan ini antara lain: pose sukhasana, padmasana, siddhasana, dan vajrasana.

Latihan ini paling sedikitnya dilakukan selama kurang lebih 5-15 menit dalam setiap harinya dan akan menimbulkan perubahan dalam tubuh menjadi lebih rileks dan segar serta dapat mengurangi stress melalui pelepasan hormon kortisol. Latihan ini dapat menguatkan sistem pernapasan, menenangkan sistem saraf, menguatkan sistem kekebalan tubuh dan mengurangi tingkat stress (Aryadi, 2018).

Latihan pernapasan yoga sama dengan dengan latihan pernapasan dalam yang sering dipraktekkan di lingkungan keperawatan (Nur, 2019). Namun, pada yoga pranayama terdapat latihan pernapasan lainnya yaitu yang memasukkan unsur-unsur spiritualitas pada akhir latihan (Sukarno, 2017).

Hasil evaluasi efek klinis terapi yoga pranayama pada pasien PPOK yang diteliti pada beberapa studi menunjukkan efek perbaikan positif pada fungsi paruparu dan kapasitas latihan yang berpotensi menjadi program rehabilitasi paru tambahan untuk pasien dengan PPOK (Gupta et al., 2014; Kaminsky et al., 2017). Berdasarkan studi Ranjita et al., (2016), menunjukkan efek terapi yoga pranayama selama 12 minggu pada pekerja tambang dengan PPOK seperti penurunan dispnea, kelelahan, dan peningkatan performa fungsional.

Hal ini sejalan dengan penelitian Singh \& Tripathi (2017) yang menunjukkan terapi yoga pranayama selama 6 minggu pada pasien PPOK rawat jalan memiliki kelebihan dapat menurunkan respiratory rate, meningkatkan Forced Expiratory Volume (FEV), serta peningkatan waktu menahan nafas. Terjadinya perbaikan yang signifikan dan progresif pada tanda-tanda vital serta kemampuan fungsional paru pada pasien PPOK seperti $\mathrm{SpO} 2$ dan denyut nadi pada kelompok perlakuan intervensi yoga mengindikasikan efektivitas dari yoga pranayama (Ranjita et al., 2016).

Mekanisme yang menjelaskan efek latihan yoga terhadap peningkatan fungsi paru penderita PPOK lumayan kompleks dan saling berkaitan antara efek satu dengan efek lainnya untuk menghasilkan suasana rileks dan kebugaran serta sinergi antara pikiran, jiwa dan tubuh. Yoga pranayama yang dapat dilakukan secara sederhana adalah 
JURNAL ILMU KESEHATAN BHAKTI HUSADA:

HEALTH SCIENCES JOURNAL

VOL. 12 NO. 02, DESEMBER 2021

DOI: $10.34305 / J I K B H . V 12 I 2.342$
Ciptaan disebarluaskan di bawah

Lisensi Creative Commons Atribusi-

NonKomersial-BerbagiSerupa 4.0

Internasional. melalui pengontrolan pernapasan, energi, melakukan meditasi, dan relaksasi. Pernapasan yang dilakukan merupakan pernapasan lembut dan teratur melalui kombinasi dari beberapa otot dalam tubuh seperti otot perut, bahu dan dada, sehingga pasien dapat mampu mengambil napas lebih dalam lagi, yang kemudian akan menghasilkan perbaikan pada modulasi saraf parasimpatik, sensitivitas kemoreseptor dan saraf simpatetik. Penurunan reaktivitas saraf simpatetik yang membantu dilatasi bronkus dan memperbaiki pernapasan abnormal. Perbaikan pola pernapasan membantu ekspansi alveoli dan melatih kelenturan jaringan paru (Ranjita et al., 2016). Hasil yang didapatkan yaitu meningkatkan fungsi ventilasi, mengurangi kekurangan oksigen (hipoksia) serta meningkatkan pertukaran gas, sehingga menurunkan dyspnea pada penderita PPOK (Liu et al., 2014; Singh \& Tripathi, 2017).

Pernafasan yang baik akan membantu mengefisienkan tingkat toleransi latihan pada penderita PPOK. Test jalan dengan jarak 6 menit / 6-minute walking distance (6MWD) merupakan parameter sederhana dan valid untuk mengukur tingkat toleransi aktivitas pasien (Papp et al., 2017). Berdasarkan hasil studi $\mathrm{Wu}$ et al., (2018) yang menunjukkan peningkatan dengan ratarata jarak 35 meter dari sebelumnya 19 meter pada kelompok intervensi yoga. Hasil tersebut didukung oleh studi Kaminsky et al., (2017) yang menyatakan peningkatan kapasitas latihan 6-MWD yang sebelumnya 25 menit, meningkat menjadi 39 menit.

Perbaikan pada bagian kardiorespiratori diikuti dengan peningkatan performa fisik yang meliputi perbaikan kekuatan otot rangka, fleksibilitas, daya tahan, koordinasi, dan stabilitas homeostasis (Cramer et al., 2019). Pengaruh yoga pranayama pada sistem kardiopulmoner berpengaruh penting terhadap peningkatan saturasi oksigen serta pengoptimalan denyut nadi. Relaksasi otot dan pengoptimalan saraf simpatik dan parasimpatik berpengaruh dalam aktivitas kardiorespirasi. Peningkatan kapasitas udara di paru-paru akan membantu meningkatkan penghantaran oksigen ke jaringan dan membantu modulasi saraf otonom jantung yang membantu perbaikan kontrol homeostasis tubuh termasuk denyut nadi (Wu et al., 2018). 
JURNAL ILMU KESEHATAN BHAKTI HUSADA:

HEALTH SCIENCES JOURNAL

VOL. 12 NO. 02, DESEMBER 2021

DOI: $10.34305 / J I K B H . V 12 I 2.342$

\section{Kesimpulan dan Saran}

Dari 7 jurnal utama yang di analisis oleh penulis didapatkan bahwasanya terapi yoga pranayama merupakan salah satu tindakan yang efektif sebagai upaya rehabilitative paru penderita PPOK. Latihan pernapasan yoga pranayama sendiri berfungsi untuk merelaksasikan otot pernapasan dengan menciptakan suasana relaksasi melalui pelepasan hormone serotonin, dopamine dan endorphin. Terapi ini juga dapat membantu penderita PPOK untuk meningkatkan kebugaran, kontrol energi serta memperbaiki tingkat kelelahan melalui peningkatan efisiensi kardiovaskuler dan kontrol homeostasis tubuh. Terapi ini juga tergolong sederhana dan mudah untuk dilaksanakan tanpa efek samping. Oleh karena itu, terapi ini sangat berpotensi untuk menjadi terapi rehabilitatif pada penderita PPOK.

Lembaga penelitian dan pendidikan perlu melakukan penelitian lebih lanjut terkait efektivitas latihan pernapasan yoga pranayama sebagai terapi rehabilitative paru pada penderita PPOK. Sehingga nantinya terapi ini dapat disebarluaskan dan diimplementasikan
Ciptaan disebarluaskan di bawah

Lisensi Creative Commons Atribusi-

NonKomersial-BerbagiSerupa 4.0

Internasional.

oleh masyarakat luas, sehingga para penderita PPOK dapat dihindarkan dari gangguan kesehatan yang lebih lanjut akibat komplikasi yang dideritanya, dan penderita dapat tetap menjaga kebugaran fisik serta psikisnya.

\section{Daftar Pustaka}

Aryadi, I. P. H. (2018). Yoga Pranayama dan Terapi Musik: Sebuah Kombinasi Terapi Rehabilitatif Holistik pada Penderita Penyakit Paru Obstruktif Kronis (PPOK). Universitas Udayana, 1-25.

Balach, A., Anita, H., Shailaja, P., Surekharani, C., \& Shashikala, G. V. (2011). Effect of Short Term Pranayama and Meditation on Respiratory Parameters in Healthy Individuals. International Journal of Collaborative Research on Internal Medicine \& Public Health, 3(6), 0.

Cramer, H., Haller, H., Klose, P., Ward, L., Chung, V. C. H., \& Lauche, R. (2019). The Risks and Benefits of Yoga for Patients with Chronic Obstructive Pulmonary Disease: A Systematic Review and MetaAnalysis. Clinical Rehabilitation, 33(12), 1847-1862.

Gupta, A., Gupta, R., Sood, S., \& Arkham, M. (2014). Pranayam for Treatment of Chronic Obstructive Pulmonary Disease: Results From A Randomized, Controlled Trial. Integrative Medicine: A Clinician's Journal, 13(1), 26. 
JURNAL ILMU KESEHATAN BHAKTI HUSADA:

HEALTH SCIENCES JOURNAL

VOL. 12 NO. 02, DESEMBER 2021

DOI: $10.34305 / J I K B H . V 12 I 2.342$

Kaminsky, D. A., Guntupalli, K. K., Lippmann, J., Burns, S. M., Brock, M. A., Skelly, J., DeSarno, M., Pecott-Grimm, H., Mohsin, A., \& LaRock-McMahon, C. (2017). Effect of Yoga Breathing (Pranayama) on Exercise Tolerance in Patients with Chronic Obstructive Pulmonary Disease: A Randomized, Controlled Trial. The Journal of Alternative and Complementary Medicine, 23(9), 696-704.

Kementerian Kesehatan Republik Indonesia. (2019). Profil Kesehatan Indonesia 2018. Kementerian Kesehatan Republik Indonesia.

Liu, X.-C., Pan, L., Hu, Q., Dong, W.-P., Yan, J.-H., \& Dong, L. (2014). Effects of Yoga Training in Patients with Chronic Obstructive Pulmonary Disease: A Systematic Review and Meta-Analysis. Journal of Thoracic Disease, 6(6), 795.

Maharani, N. P. R. A. (2020). Pranayama Sebagai Sains Spiritual. Jurnal Yoga dan Kesehatan, 2(2), 110-117.

Nur, A. (2019). Pengaruh Kombinasi Latihan Yoga Pranayama dan Endurance Exercise terhadap Peningkatan Arus Puncak Ekspirasi Paksa dan Kontrol Asma di Rumah Sakit Universitas Airlangga dan Rumah Sakit Umum Haji Surabaya. Universitas Airlangga.

Papp, M. E., Wandell, P. E., Lindfors, P., \& Nygren-Bonnier, M. (2017). Effects of Yogic Exercises on Functional Capacity, Lung Function and Quality of Life in Participants with Obstructive Pulmonary
Ciptaan disebarluaskan di bawah

Lisensi Creative Commons Atribusi-

NonKomersial-BerbagiSerupa 4.0

Internasional.

Disease: A Randomized Controlled

Study. Eur $J$ Phys Rehabil Med, 53(3), 447-461.

Perhimpunan Dokter Paru Indonesia. (2011). Tuberkulosis; Pedoman Diagnosis dan Penatalaksanaan di Indonesia. Perhimpunan Dokter Paru Indonesia.

Rahman, F., \& Bintari, R. P. (2020). Program Fisioterapi Komprehensif pada Penyakit Paru Obstruksi Kronis (PPOK) Eksaserbasi Akut. FISIO MU: Physiotherapy Evidences, 1(2), 83-88.

Ranjita, R., Hankey, A., Nagendra, H. R., \& Mohanty, S. (2016). Yoga-Based Pulmonary Rehabilitation for the Management of Dyspnea in Coal Miners with Chronic Obstructive Pulmonary Disease: A Randomized Controlled Trial. Journal of Ayurveda and Integrative Medicine, 7(3), 158-166.

Sindhu, P. (2015). Panduan Lengkap Yoga: Untuk Hidup Sehat dan Seimbang. Mizan Qanita.

Singh, S., \& Tripathi, J. S. (2017). Effect of 6 Weeks of Pranayama on Force Vital Capacity of Person with Chronic Obstructive Pulmonary Disease. Int. J. Phy. Edu. Spo, 2(3), 4-10.

Sukarno, M. A. U. S. (2017). Efek Latihan Pernafasan Yoga (Pranayama) terhadap Dyspnea Pasien PPOK. Adi Husada Nursing Journal, 3(1), 68-72.

World Health Organization. (2021). 
JURNAL ILMU KESEHATAN BHAKTI HUSADA:

HEALTH SCIENCES JOURNAL

VOL. 12 NO. 02, DESEMBER 2021

DOI: $\underline{10.34305 / J I K B H . V 12 I 2.342}$
Ciptaan disebarluaskan di bawah

Lisensi Creative Commons Atribusi-

NonKomersial-BerbagiSerupa 4.0

Internasional.

Chronic Obstructive Pulmonary

Disease (COPD). World Health Organization.

https://www.who.int/news-

room/fact-sheets/detail/chronic-

obstructive-pulmonary-disease-

(copd)

Wu, L.-L., Lin, Z.-K., Weng, H.-D., Qi, Q.-F., Lu, J., \& Liu, K.-X. (2018). Effectiveness of Meditative Movement on COPD: A Systematic Review and Meta-Analysis. International Journal of Chronic Obstructive Pulmonary Disease, 13, 1239.

Zulkarni, R., Nessa, N., \& Athifah, Y. (2019). Analisis Ketepatan Pemilihan dan Penentuan Regimen Obat pada Pasien Penyakit Paru Obstruktif Kronis (PPOK). Jurnal Sains Farmasi \& Klinis, 6(2), 158163. 